\title{
Pengaruh Struktur Kewenangan, Karakteristik Sistem Informasi Keuangan Daerah dan Perilaku Manajer Terhadap Kesadaran Akan Biaya (Studi Empiris Pada Pemerintah Kota Solok)
}

\author{
Mutiara Candra \\ Program Studi Magister Akuntansi Fak. Ekonomi Universitas Andalas \\ Correspondence email: mutiaracandra@yahoo.com
}

\begin{abstract}
Abstrack. This research aimed to identify and to get empirical evidence of the effect of the structure of authority that is broken down into formal and informal authority structures, the characteristics of regional financial information systems and managers' behavior on cost consciousness. This study was 37 SKPD registered in Solok city with a total sample of 74 people consisting of leaders and treasurer office / agency / office at SKPD in Solok city. Dependent variable in this research is the cost consciousness and independent variable that is authority structure (structure of formal authority and structure of informal authority), Characteristics of regional financial information systems and manager behavior. The hypothesis is tested by using multiple regression analysis using SPSS version 14. This study shows the test results that manager behavior does not affect the cost consciousness, while formal, informal authority structures and Regional financial information systems have a significant effect on the cost consciousness.
\end{abstract}

Keywords: Cost Awareness, Formal Authority Structure, Informal Authority Structure, Regional Financiallnformation System Characteristics, Manager Behavior

\section{PENDAHULUAN}

Pemerintah daerah merupakan lembaga yang menjalankan roda pemerintah yang sumber pengesahannya berasal dari masyarakat. Kepercayaan yang diberikan oleh masyarakat kepada penyelenggara pemerintah harus diimbangi dengan kinerja yang baik, sehingga pelayanan dapat ditingkatkan secara efektif dan menyentuh pada masyarakat. Untuk pemerintah daerah, penilaian kinerja menjadi sorotan banyak pihak terlebih dengan adanya desentralisasi atau disebut juga dengan otonomi daerah yang memberikan kewenangan lebih luas kepada pemerintah daerah untuk mengatur dan mengurus sendiri urusan pemerintah dan kepentingan masyarakat setempat seperti yang diamanatkan dalam UU nomor 32 Tahun 2004 tentang Pemerintah Daerah.Tuntutan agar instansi pemerintah daerah untuk dapat mengukur kinerja semakin besar dengan dikeluarkannya Peraturan Pemerintah Nomor 105 Tahun 2000 tentang Pengelolaan Daerah, yang diganti dengan PP Nomor 58 Tahun 2005 tentang Tata Cara Pertanggung jawaban Kepala Daerah. Bergulirnya Undang-Undang nomor 22 Tahun 1999 Pemerintah Daerah dan Undang-Undang Nomor 25 Tahun 1999 tentang Perimbangan Keuangan Pemerintahan Pusat dan Daerah, dan aturan pelaksanaannya Pemerintah mengeluarkan Undang-Undang RI Nomor 33 Tahun 2004 tentang Perimbangan Keuangan antara Pemerintah Pusat dan Pemerintah Daearah. Pembentukan Undang-Undang Perimbangan Keuangan antara Pemerintah Pusat dan Pemerintah Daerah ini di maksudkan untuk mendukung pendanaan atas penyerahan urusan kepada Pemerintah Daerah yang diatur dalam Undang-Undang tentang Pemerintah Daerah. Sebagai pelaksanaan Undangundang Nomor 33 Tahun 2004 tentang Perimbangan Keuangan antara Pusat dan Pemerintah Daerah mengamanatkan adanya dukungan Sistem Informasi Keuangan Daerah (SIKD) untuk menunjang perumusan kebijakan fiskal secara nasional serta meningkatkan transparansi dan akuntanbilitas dalam pelaksanaan desentralisasi.

Informasi dilihat dari sudut pandang akuntansi dapat berpengaruh terhadap pengambilan keputusan oleh pemakai user, atau dengan kata lain akuntansi berorientasi pada tindakan. Akuntansi dianggap suatu proses yang berkaitan dengan perilaku dan tidak dapat dilepaskan dari perilaku manusia atau organisasi yang membutuhkan informasi yang dihasilkan oleh akuntansi tersebut, (Endang, 2004). Suatu organisasi perlu merancang desain organisasi untuk mencapai tujuannya. Desain organisasi adalah sebuah proses memilih dan mengelola aspek struktural dan budaya termasuk karakteristik informasi yang dilakukan para manajer sehingga organisasi mampu mengendalikan kegiatan apa yang perlu dilakukan untuk mencapai tujuan bersama (Yohanes, 2012). Menurut Khomsiah (2000), sistem akuntansi berguna dalam pengambilan keputusan atau manajemen keputusan dan mengendalikan perilaku, sistem akuntansi tidak hanya menyajikan fungsi keputusan manajemen dengan menyediakan informasi untuk mengurangi kondisi ketidakpastian, namun juga memungkinkan pembuat keputusan untuk meningkatkan berbagai alternatif pilihan tindakan dengan kualitas informasi yang lebih baik, desain sistem informasi akuntansi merupukan bagian dari sitem pengendalian organisasi, yang perlu mendapat perhatian, sehingga dapat memberikan kontribusi positif dalam mendukung keberhasilan sistem pengendalian. Penggunaan sistem pengendalian tersebut memungkinkan 
Mutiara Candra, Pengaruh Struktur Kewenangan, Karakteristik Sistem Informasi Keuangan Daerah dan Perilaku Manajer Terhadap Kesadaran Akan Biaya (Studi Empiris Pada Pemerintah Kota Solok)

para manajer dapat membuat keputusan-keputusan yang lebih baik, mengontrol operasi-operasi dengan efektif, maupun mengestimasi biaya dan profitabilitas keberhasilan tertentu sehingga dapat meningkatkan kinerja.

\section{METODE}

Populasi dalam penelitian ini adalah Satuan Kerja Perangkat Daerah (SKPD) di Kota Solok. Berdasarkan data yang diperoleh dari LAKIP Pemerintah Kota solok jumlah Satuan Kerja yang terdapat berjumlah 35 SKPD yang terdiri dari Dinas, Badan, Kantor, Kecamatan, dan Inspektorat. Sampel dalam penelitian ini adalah seluruh SKPD yang terdiri dari 74 orang yang terdiri dari pimpinan dan bendahara pada setiap SKPD yang terdaftar di Kota Solok. Penelitian ini menggunakan metode total sampling dikarenakan populasinya kurang dari 100 subjek. Responden pada penelitian ini adalah manajer tingkat menengah pada pemerintahan seperti, kepala SKPD, kepala bagian, staf ahli dan camat.

\section{HASIL}

Dari 74 kuesioner yang disebar sebanyak $8(10,9 \%)$ kuesioner tidak kembali dan hanya kembali $66(89,1 \%)$ kuesioner, dari jumlah kuesioner yang kembali tidak ditemukan kuesioner yang rusak (0\%). Maka jumlah kuesioner yang dapat diolah 66 kuesioner.

Tabel 1

Uji Deskriptif

\begin{tabular}{lccrr}
\hline \multicolumn{1}{c}{ Variabel } & Kisaran Teoritis & Kisaran Aktual & Mean & Std. Deviation \\
\hline Kesadaran Akan Biaya $(\mathrm{Y})$ & $7-49$ & $28-45$ & 36,8333 & 4,42922 \\
Struktur Kewenangan Formal $\left(\mathrm{X}_{\mathrm{1a}}\right)$ & $3-21$ & $7-15$ & 11,9242 & 2,20007 \\
Struktur Kewenangan Informal $\left(\mathrm{X}_{\mathrm{b}}\right)$ & $5-35$ & $20-34$ & 26,3030 & 3,42825 \\
Sistem Informasi Keuangan Daerah $\left(\mathrm{X}_{2}\right)$ & $9-63$ & $34-57$ & 46,5909 & 5,32621 \\
Perilaku Manajer $\left(\mathrm{X}_{3}\right)$ & $8-56$ & $30-48$ & 41,1364 & 4,83540 \\
\hline
\end{tabular}

Sumber: data primer yang diolah, 2017

Analisis deskriptif digunakan penelitian untuk memudahkan penelitian dalam merangkum hasil penelitian, pada tabel di atas dapat disimpulkan bahwa pada variabel kesadaran akan biaya (Y) nilai teoritis berkisar antara $7 \mathrm{~s} / \mathrm{d}$ 49, kisaran aktual berkisar antara $28 \mathrm{~s} / \mathrm{d} 45$ dan nilai mean sebesar 36,8333 sedangkan std. Deviation sebesar 4,42922, pada variabel struktur kewenangan formal $\left(\mathrm{X}_{1 \mathrm{a}}\right)$ nilai teoritis berkisar antara $3 \mathrm{~s} / \mathrm{d} 21$, kisaran aktual berkisar antara 7 s/d 15 dan nilai mean sebesar 11, 9242 sedangkan standar deviation sebesar 2,20007. Pada variabel struktur kewenangan informal $\left(\mathrm{X}_{1 \mathrm{~b}}\right)$ nilai teoritis berkisar antara $5 \mathrm{~s} / \mathrm{d} 35$, kisaran aktual berkisar antara $20 \mathrm{~s} / \mathrm{d} 34$ dan nilai mean sebesar 26,3030 sedangkan standar deviation sebesar 3,42825, pada variabel sistem informasi keuangan daerah $\left(\mathrm{X}_{2}\right)$ nilai teoritis berkisar antara $9 \mathrm{~s} / \mathrm{d}$ 63, kisaran aktual berkisar antara $34 \mathrm{~s} / \mathrm{d} 57$ dan nilai mean sebesar 46,5909 sedangkan standar deviation sebesar 5, 32621, dan pada variabel perilaku manajer $\left(\mathrm{X}_{3}\right)$ nilai teoritis berkisar antara 8 s/d 56, kisaran aktual berkisar antara $30 \mathrm{~s} / \mathrm{d} 48$ dan nilai mean sebesar 41,1364 sedangkan standar deviation 4,83540.

\section{Pengaruh Struktur Kewenangan Formal terhadap Kesadaran Akan Biaya}

Pengujian hipotesis pertama dilakukan dengan membandingkan nilai statistik yang diperoleh dengan Alpha. $\mathrm{Hal}$ ini dapat dilihat bahwa nilai signifikan sebesar 0,000 lebih kecil dari Alpha. Nilai koefesien $\beta$ dari variabel $\mathrm{X}_{1 \mathrm{a}}$ bernilai positif yaitu 0,067 . Jadi hipotesis telah dirumuskan sesuai dengan hasil penelitian yang dilakukan sehingga $\mathrm{H}_{1 \mathrm{a}}$ diterima dan $\mathrm{H}_{0}$ ditolak. Hasil penelitian yang peneliti lakukan sejalan dengan hasil penelitian yang dilakukan oleh para peneliti sebelumnya diantaranya yaitu : penelitian Kusuma (2011), Atarwan (2008), Syafruddin (2006), Chairina (2007) yang menemukan hasil bahwa struktur kewenangan formal berpengaruh terhadap kesadaran akan biaya.

\section{Pengaruh Struktur Kewenangan Informal terhadap Kesadaran Akan Biaya}

Pengujian hipotesis kedua dilakukan dengan membandingkan nilai statistik yang diperoleh dengan Alpha. Hal ini dapat dilihat bahwa nilai signifikan sebesar 0,000 lebih kecil dari Alpha. Nilai koefisien $\beta$ dari variabel $\mathrm{X}_{\mathrm{bb}}$ bernilai positif yaitu 0,706. Jadi hipotesis telah dirumuskan sesuai dengan hasil penelitian yang dilakukan sehingga $\mathrm{H}_{1 \mathrm{~b}}$ diterima $\mathrm{H}_{0}$ ditolak. Hasil penelitian yang peneliti lakukan tidak sejalan dengan hasil penelitian yang dilakukan oleh para peneliti sebelumnya diantaranya yaitu : penelitian Kusuma (2011), Atarwan (2008), Syafruddin (2006), Chairina (2007) yang menemukan hasil bahwa struktur kewenangan informal tidak berpengaruh terhadap kesadaran akan biaya.

\section{Pengaruh Karakteristik Sistem Informasi Keuangan Daerah terhadap Kesadaran Akan Biaya}

Pengujian ini dilakukan dengan membandingkan nilai statistik yang diperoleh dengan Alpha. Hal ini dapat dilihat bahwa nilai signifikan sebesar 0,001 lebih kecil dari Alpha. Nilai koefisien $\beta$ dari variabel $\mathrm{X}_{2}$ bernilai positif 
yaitu 0,364. Jadi hipotesis telah dirumuskan sesuai dengan hasil penelitian yang dilakukan sehingga $\mathrm{H}_{2}$ diterima $\mathrm{H}_{0}$ ditolak. Hasil penelitian yang peneliti lakukan sejalan dengan hasil penelitian yang dilakukan oleh para peneliti sebelumnya diantaranya yaitu : penelitian Kusuma (2011), Atarwan (2008), Syafruddin (2006), Chairina (2007) yang menemukan hasil bahwa karakteristik sistem informasi keuangan daerah berpengaruh terhadap kesadaran akan biaya.

\section{Pengaruh Perilaku Manajer Terhadap Kesadaran Akan Biaya}

Pengujian ini dilakukan dengan membandingkan nilai statistik yang diperoleh dengan Alpha. Hal ini dapat dilihat bahwa nilai signifikan sebesar 0,163 lebih besar dari Alpha. Nilai koefesien $\beta$ dari variabel $\mathrm{X}_{3}$ bernilai negatif yaitu -0,107. Jadi hipotesis telah dirumuskan sesuai dengan hasil penelitian yang dialkukan sehingga $\mathrm{H}_{3}$ ditolak $\mathrm{H}_{0}$ diterima. Laporan keuangan dijadikan pertimbangan penting dalam mencapai anggaran atau dalam mengefesienkan biaya. Hasil penelitian yang peneliti lakukan tidak sejalan dengan hasil penelitian yang dilakukan oleh para peneliti sebelumnya diantaranya yaitu : penelitian Kusuma (2011), Atarwan (2008), Marlisa dkk (2010) yang menemukan hasil bahwa perilaku manajer berpengaruh positif terhadap kesadaran akan biaya.

\section{SIMPULAN}

Penelitian ini berisikan suatu model yang menguji pengaruh struktur kewenangan formal, struktur kewenangan informal, karakteristik sistem informasi keuangan daerah dan perilaku manajer terhadap kesadaran akan biaya. Dari pengujian regresi berganda dengan menggunakan SPSS, dapat disimpulkan bahwa, penelitian ini menunjukan hasil uji bahwa perilaku manajer tidak berpengaruh terhadap kesadaran akan biaya, sedangkan struktur kewenangan formal, informal dan sistem informasi keuangan daerah berpengaruh signifikan terhadap kesadaran akan biaya.

\section{DAFTAR PUSTAKA}

Atarwan, J. D. Rita, (2008), Pengaruh struktur kewenangan, karakteristik sistem informasi keuangan daerah dan perilaku manajer terhadap kesadaran akan biaya, tesis S2, UNDIP.

Baridwan, Zaki, (2013). Sistem Informasi Akuntansi, edisi kedua, Yogyakarta, BPFE.

Bodnar, George H, William S Hopwood, (2010), Accounting Information System, United Stateof America, Pearson Education, Inc., Publishing as Prentice Hall.

Brigham, E.F dan Houston, (2006), Dasar-dasar Manajemen Keuangan, Edisi Sepuluh, Alih Bahasa Ali Akbar Yulianto, Penerbit Salemba Empat, Jakarta.

Chairina, (2007), Pengaruh kekuasaan dan desain organisasi terhadap perilaku manajer, jurnal ekonomi dan bisnis Indonesia, vol.22, no.3, 319-342

Dehghanzade H., Moradi, M.A., dan Raghibi, M, (2011), A Survey of Human Factors' Impacts on the Effectiveness of Accounting Information Systems, International Journal of Business Administration. Vol. 2, No. 4.

Endang, R., (2004), Analisis pengaruh ketidak pastian lingkungan dan kultur organisasional sebagai variabel moderating terhadap hubungan informasi akuntansi terhadap kinerja manajerial, tesis program pasca sarjana magister sains akuntansi universitas diponegoro (tidak dipublikasikan).

Ghozali, Imam., (2013), SPSS 21, Aplikasi Analisis Multivariate dengan Program SPSS, Edisi ketujuh, Semarang, Unversitas Diponegoro.

Gudono, (2012), Teori Organisasi, Edisi 2, BPFE, Yogyakarta.

Hall, James, (2011), Sistem Informasi Akuntansi, Edisi Empat, Salemba Empat, Jakarta.

Handoko, T. Hani dkk (2012), Manajemen Dalam Berbagai Perspektif, Penerbit Erlangga, Jakarta.

Hansen, R, Don, Mowen, M, Maryanne, (2009), Akuntansi Manajerial, Buku Satu, Edisi Kedelapan, jakarta, Salemba Empat.

Hasibuan, (2010), Manajemen Sumber Daya Manusia, Jakarta, Bumi Aksara.

Sunandar, Imam, (2013), "Tahap -Tahap Pengembangan Sistem Informasi", (http://imansunandar14.blogspot.com/2013/05/tahap-tahap-pengembangan- sistem.html)

Ibrahim, J. T., (2003), Sosiologi Pedesaan, Penerbit Universitas Muhammadiyah Malang.

Ivancevich, dkk, (2008), Organisasi, Perilaku, Struktur, Proses. Bina Rupa Aksara.Jakarta.

Kusuma, Wira Ade dkk (2011), Pengaruh Struktur Kewenangan, Sistem Informasi Keuangan Daerah dan Periraku Manajer terhadap Kesadaran Akan Biaya,jurnal Sorot No.1, April, ISSN 1907-364X, Jurusan Akuntansi, Fakultas Ekonomi, Universitas Riau.

Khomsiyah \& Nur Indriantoro, (2000), Aspek perilaku penganggaran partisipatif, jurnal akuntansi dan auditting indo, vol.3, no.2, des. Pp. 123-133.

Laporan Akuntabilitas Kinerja Instansi Pemerintah (LAKIP) Kota Solok, 2016 
Mutiara Candra, Pengaruh Struktur Kewenangan, Karakteristik Sistem Informasi Keuangan Daerah dan Perilaku Manajer Terhadap Kesadaran Akan Biaya (Studi Empiris Pada Pemerintah Kota Solok)

Luayyi, S., (2010), Teori Keagenan dan Manajemen Laba dari Sudut Pandang Etika Manajer, EL-MUHASABA Vol.1 No.2

Lubis, Arfan Ikhsan, (2010), Akuntansi Keprilakuan, Edisi Dua, Penerbit Salemba Empat, Jakarta.

Lukviarman, Niki., (2006), Dasar-Dasar Manajemen Keuangan, Andalas University, Press, Padang.

Marlisa, dkk (2010), Analisis Pengaruh Perilaku Manajerial Manajer Terhadap Kerugian Perusahaan (Studi Kasus Pada PDAM Tirta Buana Merangin), Jurnal Cakrawala Akuntansi, Vol.2, No.1, Jurnal Akuntansi Fakultas Ekonomi Universitas Jambi.

Mulyadi, (2002), Auditing Buku 1, Edisi Keenam, Jakarta, Salemba Empat.

Peraturan Pemerintah Nomor 11 tahun 2001 tentang Informasi Keuangan Daerah. (www.djpk.depkeu.go.id).

Peraturan Pemerintah Nomor 58 Tahun 2005 tentang Tata Cara Pertanggung jawaban Kepala Daerah, Melalui (www.jdih.kemenkeu.go.id). 